\title{
Oficinas de fotos: experiências brasileiras em clínica da atividade
}

\author{
Claudia Osorio $^{\mathrm{I}, 1}$, Ariele Binoti Pacheco ${ }^{\mathrm{II}, 2}$ e Maria Elizabeth Barros de Barros ${ }^{\mathrm{II}, 3}$ \\ ${ }^{\mathrm{I}}$ Universidade Federal Fluminense (Rio de Janeiro, RJ)

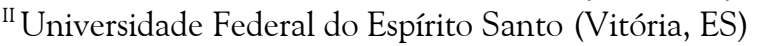

\begin{abstract}
O texto apresenta o método da oficina de fotos em duas experiências distintas de análise do trabalho: em um hospital e em uma empresa de granito e mármore. O relato das experiências dá ensejo à discussão do método proposto pelas autoras, bem como da metodologia da clínica da atividade e suas possibilidades de intervenção e transformação das situações de trabalho.
\end{abstract}

Palavras-chave: Clínica da atividade, Análise do trabalho, Metodologia, Método.

Workshops of photography: Brazilian experiences in clinic of activity

This paper presents the method of a workshop of photography in two distinct experiences of analysis of work: in a hospital and in a company that produces granite and marble. The report of these experiences is an opportunity for discussion on the method proposed by the authors. The methodology of clinic of activity and its possibilities for intervention and transformation of work are also discussed.

Keywords: Clinic of activity, Work analysis, Methodology, Method.

\section{Introdução}

$\mathrm{D}$ esde 2004, vimos experimentando a oficina de fotos como um caminho para a análise do trabalho (Osorio, 2010). Interessa-nos compartilhar com grupos de trabalhadores a análise de suas próprias experiências com o objetivo de desenvolver seu poder de agir nas situações de trabalho e produzir conhecimento sobre as possibilidades desse desenvolvimento. Em especial, interessa-nos o caráter inventivo da atividade humana.

Depois da primeira experiência em um hospital público da cidade do Rio de Janeiro, seguiram-se outras, também em hospitais públicos. ${ }^{4}$ No Espírito Santo, têm sido feitas oficinas de fotos com professores do ensino médio e superior e em uma empresa de mármore e granito da região sul do estado do Espírito Santo.

Neste artigo, ${ }^{5}$ apresentaremos os principais aspectos de duas dessas experiências de uso do dispositivo clínico oficina de fotos, buscando avançar no debate acerca de sua potência como ferramenta para a ampliação da vitalidade dos coletivos de trabalho e de seus recursos para a ação.

\footnotetext{
1 Professora do Departamento de Psicologia, vinculada ao Programa de Pós-Graduação em Psicologia.

2 Pesquisadora no Programa de Pós-Graduação em Psicologia Institucional. Psicóloga do trabalho em atuação em empresa.

3 Professora do Departamento de Psicologia e do Programa de Pós-Graduação em Psicologia Institucional.

4 A partir de 2009 temos como campo empírico o Hospital Universitário Antonio Pedro, em Niterói.

5 Uma primeira versão deste trabalho foi apresentado no I Colóquio de Clínica da Atividade, em São João del-Rei, em 2010.
} 


\section{A metodologia e o método}

Nas oficinas de fotos, bem como em outros dispositivos usados na clínica da atividade (Clot, 2006, 2010), o que se propõe como metodologia é uma forma de coanálise do trabalho, praticada no ambiente habitual. É necessário considerar que o analista do trabalho é precedido nesse ambiente por aqueles que nele exercem seu ofício. Encontramos então conceitos cotidianos que organizam a experiência de trabalho, implícitos nas descrições formuladas muitas vezes em um vocabulário metafórico (Clot, 2006, pp. 125-133).

A análise do trabalho, para levar em conta a experiência dos trabalhadores, deve tomar como ponto de partida a experiência concreta do trabalho. No processo de análise coloca-se em diálogo o saber da experiência e o saber acadêmico que é trazido pelo analista do trabalho. Aqueles que têm sua atividade profissional posta em análise não transmitem aos analistas verdades inquestionáveis sobre seu trabalho. Eles se servem da presença dos analistas para se confrontar com aspectos diversos de seu trabalho, com seus possíveis e impossíveis. A experiência de trabalho pode, na análise que se caracteriza como uma nova experiência, se enriquecer, tomando o gênero de sua atividade profissional como objeto de trabalho, ou seja, como objeto de reflexão coletiva.

$\mathrm{Na}$ aproximação do trabalho como experiência, uma referência indispensável é a distinção entre trabalho prescrito e trabalho realizado. A dimensão vivida do trabalho é sempre uma (re)criação, uma novidade, não pode ser facilmente apreendida em palavras ou descrita previamente, mesmo levando em consideração o depoimento daqueles que trabalham. Não há interesse, portanto, numa análise que produza como resultado principal uma descrição.

Segundo Vygotsky (1978, citado por Litim, 2006, p. 91), "é em movimento que um corpo nos mostra o que ele é". Assim, é somente por meio de uma experimentação transformadora que a atividade de trabalho pode liberar seus segredos. É ao transformar cada realização em recurso para uma nova realização que o real da atividade se manifesta em seus desenvolvimentos (Litim, 2006). Foi nessa perspectiva que Yves Clot e Daniel Faïta (2000) propuseram a autoconfrontação cruzada como método.

Na autoconfrontação cruzada, a atividade em foco é registrada em vídeo, assim como todo o processo de análise dessa atividade. Em nossa experiência, propusemos como método registrar e analisar a atividade em fotos. $\mathrm{Na}$ oficina de fotos, os próprios trabalhadores são convidados a produzir as fotos a serem analisadas. Observa-se que a máquina fotográfica tem um efeito de distanciamento e de produção de espaço para o diálogo interior, ou seja, para um diálogo consigo e com o gênero profissional em questão. Facilita o diálogo entre pares, sem posturas individualizantes e de imputação de culpa. As fotos tomadas são discutidas com os pares e com o analista do trabalho, devendo o trabalhador-fotógrafo dizer como escolheu seu objeto, dando início ao debate com os demais participantes da oficina.

É importante destacar que a oficina de fotos é um dispositivo construído nas experiências com os trabalhadores. Não existe, portanto, um roteiro de ações que deva ser seguido, uma técnica a reproduzir. Existem direções, orientações e princípios que norteiam as ações do analista no objetivo de compartilhar com os trabalhadores a análise de suas atividades, possibilitando a ampliação de sua capacidade de ação e a transformação dos cotidianos de trabalho que produzem adoecimento.

Apresentamos a seguir, em detalhes, o encaminhamento de duas de nossas experiências. 


\section{A primeira oficina, em um hospital público da cidade do Rio de Janeiro $^{6}$}

Nossa primeira experiência de oficina de fotos foi em 2004, em um hospital do Rio de Janeiro. Essa oficina foi feita em uma manhã e teve duração de 4 horas. Foi escolhido como público-alvo o pessoal de enfermagem. Foram 15 inscritos, dos quais compareceram 12. Para fazer as fotos, usando máquinas fotográficas digitais, o grupo foi organizado em 4 subgrupos de 3 trabalhadores, com uma máquina para cada subgrupo.

Como a oficina foi oferecida pela Comissão de Saúde do Trabalhador do hospital, a proposta foi de se produzir e discutir fotos de situações positivas e fotos de situações negativas para a saúde do profissional de saúde. Ao se solicitar que a tomada de fotos tivesse essa dupla orientação, pretendia-se possibilitar que as situações vividas de forma prazerosa ${ }^{7}$ no trabalho pudessem ser ampliadas. Pretendia-se também evitar que o debate fosse marcado por falas queixosas ou de tom denunciativo.

Iniciou-se o trabalho com um jogo de "aquecimento" conhecido como "Curto/não curto". ${ }^{8}$ Nessa dinâmica, usam-se dois dados. Em um dado está escrito curto em três faces; e nas outras três não curto. No outro, faço e não faço. Cada participante lança ambos os dados simultaneamente e fala aos demais de algo em seu trabalho que gosta de fazer e que efetivamente realiza ou de alguma coisa de que gosta mas não pode realizar; e assim por diante, de acordo com as opções de combinação no resultado do lançamento dos dados.

Depois desse jogo, cada subgrupo planejou seu trabalho, delineando as situações que pretendia fotografar, e saiu para a tomada das fotos. Retornando ao local do encontro, cada subgrupo fez a seleção das fotos a serem exibidas e analisadas com todos os participantes da oficina. Cada subgrupo foi acompanhado por um "monitor", um estudante de psicologia, encarregado de dar suporte à tarefa sem interferir na escolha dos temas.

As fotos foram exibidas com um projetor e discutidas, surgindo algumas polêmicas importantes nos ofícios de enfermeira e técnica de enfermagem - algumas das quais apresentaremos a seguir.

Encerrando-se o trabalho da manhã, foi montado um painel para ser exibido em um evento científico do hospital, visando-se assim à ampliação do debate com um grupo maior de trabalhadores.

Trinta dias após o evento foi realizada uma reunião de restituição, em que foram discutidas as repercussões da oficina e do painel publicamente exibido.

$\mathrm{Na}$ oficina de fotos, as várias etapas da tarefa proposta exigem dos participantes que ponham o trabalho cotidiano em debate. $\mathrm{O}$ debate favorece que os diferentes modos possíveis de enfrentamento do real da atividade sejam postos em análise, desenvolvendo o gênero profissional e ampliando suas possibilidades como instrumento para a ação de cada um. Modos diferentes de fazer e pensar o trabalho vêm à baila quando se tem como tarefa coletiva definir o que fotografar, o que não fotografar, como fotografar as situações escolhidas, o que e como apresentar para o debate com um grupo maior. No debate que se instala, pode-se analisar algumas características do trabalho que fazem sentido para as enfermeiras, técnicas e auxiliares de enfermagem do hospital.

6 Essa experiência foi apresentada em outra publicação (Osorio, 2010) ilustrando uma discussão mais ampla de conceitos da clínica da atividade como os de gênero e estilo.

7 Relações prazerosas referem-se a relações em que há protagonismo efetivo dos trabalhadores no processo de trabalho.

8 Esse jogo nos foi apresentado pela professora Janes Herdy, colega do Departamento de Psicologia da Universidade Federal Fluminense. Não encontramos publicação com referência de autores para essa técnica. 
Assim, em várias fotos aparece o trabalho realizado em meio a relações de colaboração, principalmente interprofissional: por exemplo, o momento em que uma médica e uma enfermeira trabalham juntas em uma bancada (Foto 1).

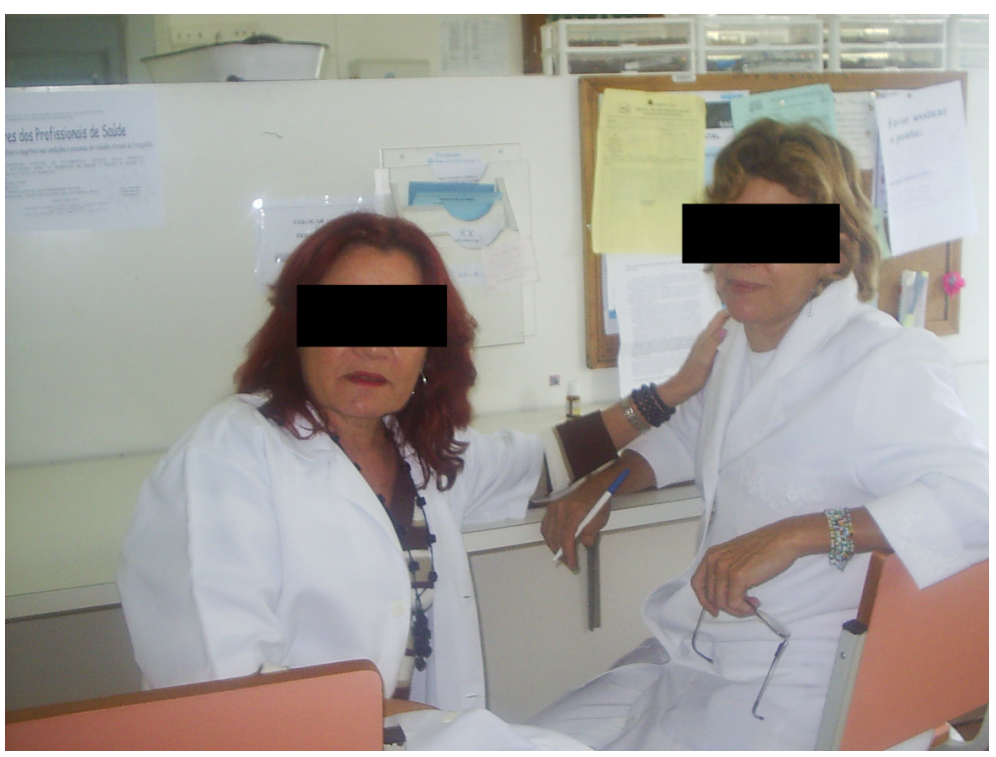

Foto 1 (Extraída de Osorio, 2010)

As polêmicas compareceram nessa análise do trabalho em equipe. Se todos concordavam que essa colaboração é necessária e desejada, os modos de ver as relações de hierarquia não se mostraram consensuais: algumas participantes consideravam a hierarquia importante, necessária, enquanto outras defenderam a construção de relações mais horizontais.

A controvérsia também esteve presente na discussão da presença de acompanhantes, em geral familiares, do doente internado (Foto 2). A foto foi tirada por um subgrupo que apresentou essa presença como positiva, mas outros participantes trouxeram as dificuldades existentes no manejo da situação.

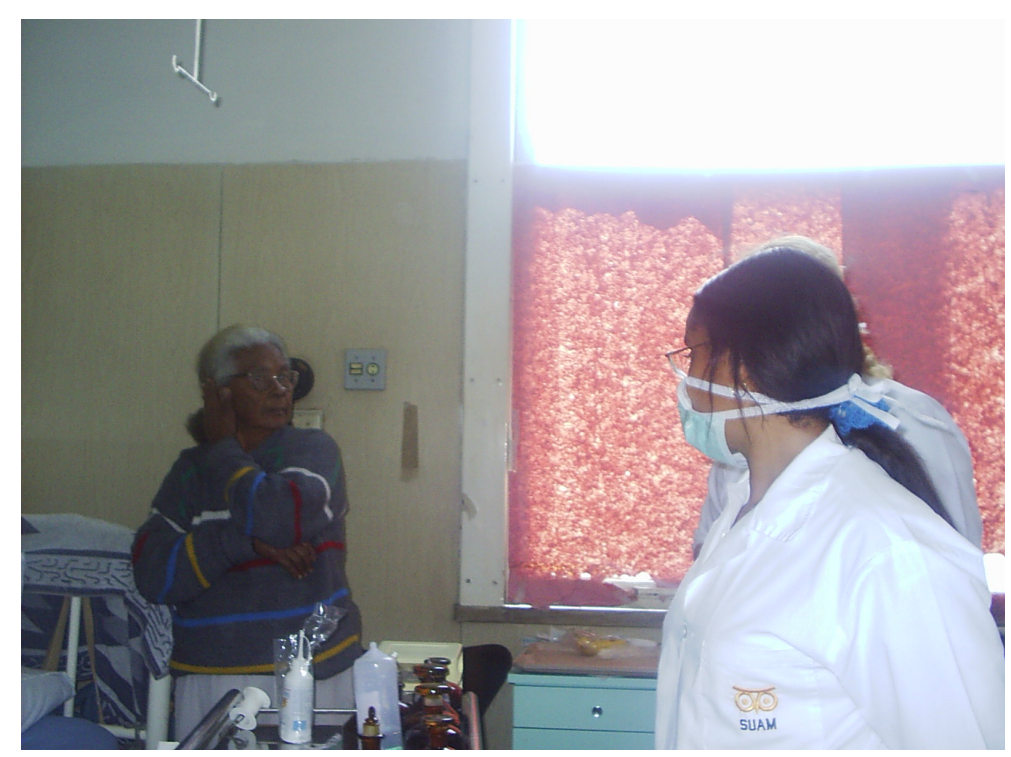

Foto 2 (Extraída de Osorio, 2010) 
Numa outra foto, a boa organização, ou a ordem, foi apresentada como facilitadora do trabalho bem-feito, algo que favorece a saúde do trabalhador de saúde. Esse é o caso de um almoxarifado do centro cirúrgico, bem equipado e com os materiais bem organizados (Foto 3). Já a desorganização foi apontada como algo que agride a saúde do trabalhador de saúde. Assim, muitas situações relacionadas à maior qualidade da atenção prestada ao doente foram apontadas como positivas para a saúde do trabalhador da assistência. Nessa análise não surgiram divergências.

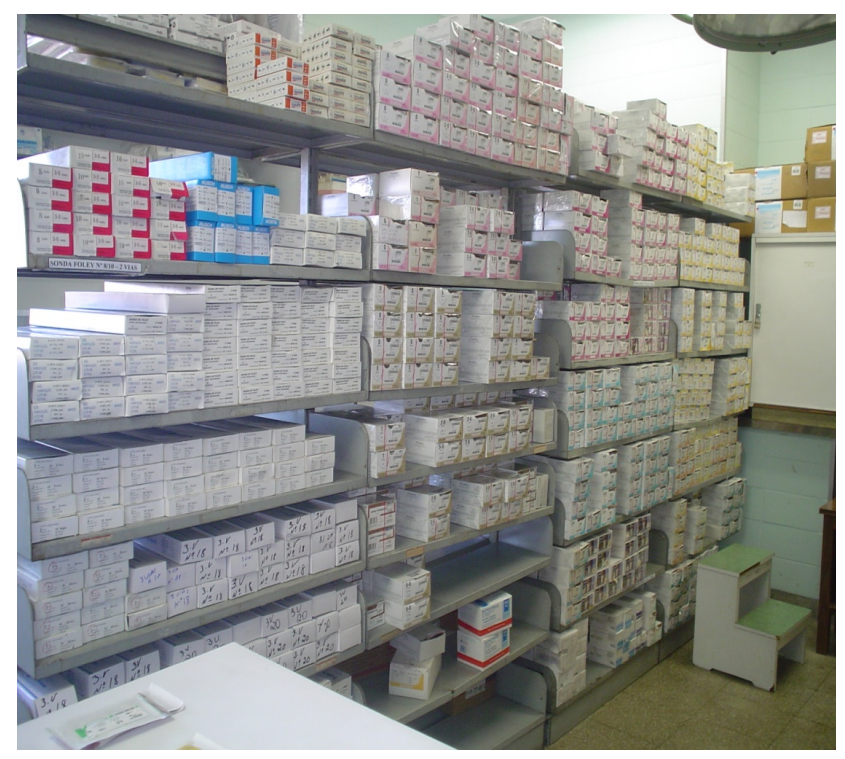

Foto 3 (Extraída de Osorio, 2010)

$\mathrm{Na}$ reunião de restituição foram discutidas as repercussões da oficina e do painel publicamente exibido.

Como transformação produzida pela experiência, foi relatado que uma equipe que não dispunha de sala de repouso em seu ambiente de trabalho havia se mobilizado para reivindicar e estava em via de obter esse espaço.

Nesse dia, os participantes trouxeram consigo alguns outros colegas que não haviam estado presentes na tomada e discussão das fotos. Foi comentada a grande repercussão do painel apresentado, que foi premiado como um dos melhores do evento. De maneira geral, foi relatado que os participantes, que constavam no painel como fotógrafos, eram cumprimentados pela iniciativa e pela pertinência das questões apontadas.

\section{A segunda oficina: caminhos trilhados na pedra9}

Uma oficina mais recente, em 2009, foi realizada em uma empresa do ramo de rochas ornamentais (granito e mármore), localizada numa pequena cidade da região sul do estado do Espírito Santo. Nessa experiência (Pacheco, 2010), a oficina de fotos tomou outros contornos.

Entre as diferentes partes do processo de extração e beneficiamento do mármore e granito, a linha de ladrilhos foi escolhida como foco da análise, principalmente porque não envolve trabalho em turnos, facilitando a organização dos encontros entre os participantes.

9 Essa experiência foi apresentada de modo mais amplo na Dissertação de Mestrado de uma das autoras deste artigo (Pacheco, 2010) e em outra publicação (Pacheco, Barros \& Osório da Silva, 2012). 
A linha de ladrilhos é composta por uma máquina de aproximadamente $70 \mathrm{~m}$ de comprimento, atravessada por uma esteira. Nela, o trabalhador coloca a chapa de pedra bruta e, após um processo de corte, polimento e bisotagem, ${ }^{10}$ os ladrilhos saem prontos. Nessa máquina trabalham nove homens nas mais diversas funções: polidor, cortador, selecionador, bisotador, calibrador e ajudante, que estão o tempo todo se comunicando e, ainda, se necessário, participando ou realizando as funções de outro trabalhador.

Com a finalidade de propor a formação de um grupo associado à pesquisa, foi realizada uma reunião com os nove trabalhadores da linha de ladrilhos. Nesta, foi proposta a realização de uma análise participativa do processo de trabalho utilizando fotografias tiradas e analisadas pelos próprios trabalhadores.

Para iniciar os debates, os participantes foram convidados a se apresentar pelo jogo conhecido como curto e não curto, já descrito.

Logo nesse primeiro encontro, foi possível perceber que o trabalho real se expande para além de qualquer tipo de prescrição. Conflitos, imprevistos, prazeres e desprazeres foram trazidos à tona e postos em debate.

O selecionador de ladrilhos disse o que curte e não faz: "Gosto quando me mandam pra selecionar ladrilho na outra máquina, porque lá tem vários tipos de material. Onde trabalho só tem um tipo". A atividade de passar as mãos e olhar o ladrilho para separar aqueles que tenham defeito torna-se menos extenuante quando o trabalhador lida com diversos tipos de materiais. Uma tarefa mais complexa parece aliviar a fadiga produzida por sua atividade habitual, tornando-se mais prazerosa.

Todos os trabalhadores da linha de ladrilhos concordaram em participar da oficina de fotos formando-se um grupo associado. Quatro participantes foram escolhidos para serem os fotógrafos.

Também nessa oficina, para dar visibilidade não apenas às estratégias que os trabalhadores encontram para se defenderem de um trabalho penoso, ${ }^{11}$ mas também às criações que eles engendram nos ambientes e processos de trabalho (Barros \& Oliveira, 2004), foi sugerido que fossem tiradas fotos de situações que os enfraquecem e os fazem sofrer no trabalho e também de situações que produzem vivacidade e que os potencializam e fortalecem no trabalho, conforme já havia sido feito na experiência no hospital, acima relatada.

Dois dias depois da primeira reunião com o grupo associado, foram realizados encontros com os quatro fotógrafos, organizados em duas duplas, para a produção das fotos. O encontro com cada dupla durou cerca de uma hora e meia.

Em todas as etapas foram feitas intervenções pela pesquisadora, confrontando-se os trabalhadores com seu próprio trabalho, ao pedir que explicassem melhor novas situações que eram trazidas para o debate, ao perguntar o que os levou a fotografar tais situações e ao pedir que descrevessem minuciosamente o processo de trabalho que gostariam de colocar em análise com toda a equipe.

Em um novo encontro, os quatro fotógrafos selecionaram as fotos a serem apresentadas ao grupo associado. De um total de 43 fotos, os fotógrafos selecionaram 12.

Os quatro trabalhadores-fotógrafos acreditavam que muitas situações fotografadas poderiam ser transformadas, se ganhassem o respaldo da direção da empresa. Mas também surgiam dúvidas: "E adianta falar? Não adianta nada!". Aos poucos, a descrença nas possibilidades de mudanças deu lugar a novas ideias, discutindo-se novas maneiras de realizar o

10 processo de bisotagem é um tipo de acabamento que consiste em retirar as quinas do ladrilho.

11 A saúde do trabalhador define os conceitos de insalubridade, periculosidade e penosidade. Cada um está relacionado a condições de riscos no ambiente de trabalho, sendo assegurado um adicional ao salário para cada trabalhador exposto ao risco. No entanto, estamos utilizando essa palavra de maneira genérica, para indicar que se trata de um trabalho cansativo, fatigante, duro. 
trabalho. A possibilidade efetiva de melhorar algumas situações de trabalho reluzia nos olhares, nos sorrisos.

No segundo encontro do grupo associado, com o objetivo de obter o apoio da direção da empresa, o gerente foi convidado pelos trabalhadores a participar.

Em geral, a equipe da linha de ladrilhos falava pouco e, na presença do gerente, quase ninguém, além dos fotógrafos, se arriscava a comentar as fotos. Respondendo à provocação da pesquisadora, aos poucos, um e outro exprimiam suas opiniões. O gerente participou bastante interessado, tentando justificar algumas ações da direção da empresa e também questionando os trabalhadores em algumas atividades que realizam, perguntava por que não seguiam algumas prescrições. À medida que os trabalhadores respondiam aos questionamentos do gerente, este se dava conta da complexidade do trabalho realizado por eles.

É importante notar que esses questionamentos não tiveram um enfoque de culpabilização, mas expressavam uma tentativa de entender o processo de trabalho e pensar em novas maneiras de fazê-lo.

Aos poucos, as hierarquias pareciam deixar de ser obstáculo para o debate; trabalhadores e gerente discutiam e pactuavam a melhor maneira para realizar as atividades de trabalho.

Uma das fotos mais discutidas (Foto 4) mostra uma máquina - um bisote - que trabalha acertando a medida do material após o corte. Normalmente, o cortador regula a máquina de corte para cortar a chapa de pedra com dois milímetros a mais. Essa máquina possui duas fresas: a primeira retira um milímetro do material e a segunda o outro milímetro, acertando a metragem do ladrilho.

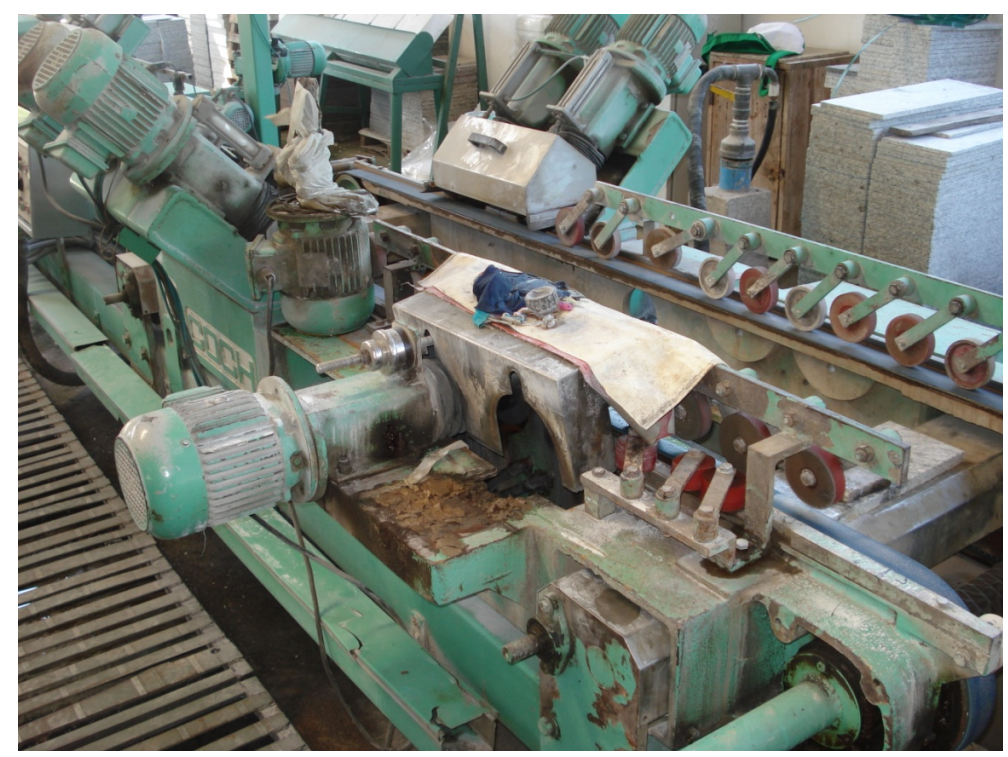

Foto 4 (Extraída de Pacheco, Barros e Osorio, 2012)

A pesquisadora fazia perguntas que os próprios trabalhadores não se fariam e, por mais simples e ingênuos que fossem os questionamentos ("O que é mesmo fresa?"), as variabilidades do processo de trabalho vinham à tona, assim como as contradições, como ter que conciliar produção, segurança e qualidade num ambiente marcado por prescrições frágeis que não dão conta, por exemplo, de guiar os trabalhadores em situações recorrentes, como a quebra/pane das máquinas.

A cena fotografada (Foto 4) mostra bem uma dessas situações recorrentes: uma máquina sem uma das fresas. Quando apenas uma das fresas atua retirando o excesso de milímetros, a 
esteira não consegue puxar o material, o que faz com que os trabalhadores precisem empurrar o material na esteira. Os trabalhadores reclamam que as máquinas estão sempre com problemas que demoram a ser resolvidos, acarretando mais esforço: a foto mostra um trabalhador ajudando o outro a empurrar os ladrilhos na esteira. Mesmo com as máquinas funcionando mal, os trabalhadores buscam modos de resolver os problemas e garantir a produção.

A falta de manutenção das máquinas e a demora para a realização de reparos levam a um excesso de trabalho, uma vez que os trabalhadores precisam se organizar para que a máquina continue a produzir com menos recursos. São renormatizações que possibilitam que as metas de produção sejam cumpridas, mas que produzem desgaste e insatisfação, quando se tornam uma exigência frequente.

Um polidor tenta traduzir em palavras o desprazer produzido pela impossibilidade de realizar sua tarefa: "Quando a máquina está com problemas, eu perco até a vontade de ir na garrafa de café".

Colocar essas questões em debate no grupo associado possibilitou o fortalecimento do coletivo. $\mathrm{O}$ debate levou os trabalhadores a pensar juntos em maneiras de transformar essas condições.

Vamos fazer uma reunião com os donos da empresa, falar sobre o problema das máquinas, vamos ver se isso resolve.

Vamos chamar o pessoal da manutenção para conversar... Será que o problema não está na falta de pessoal? Tem muita máquina aqui, ou será que é a empresa que não libera a compra de peças pras máquinas?

Ao final desse segundo encontro do grupo associado, que durou cerca de três horas, foi proposto que os fotógrafos confeccionassem um painel, para ser exibido para toda a empresa. $\mathrm{O}$ painel foi confeccionado em dois encontros. Os fotógrafos organizaram as fotos em dois grupos, com os seguintes títulos: "Alegria e satisfação gera produção" e "Prevenir é melhor que remediar". Para cada foto, foram também criadas legendas. Seis semanas após a montagem do painel, foi realizado um encontro com o grupo associado, com o objetivo de restituição, avaliando coletivamente o processo vivido até aqui. A restituição implicou, assim, uma atividade de apresentação dos resultados do encontro e discussão dos mesmos, visando a uma validação pelo coletivo de trabalhadores.

\section{A restituição e seus efeitos}

$\mathrm{Na}$ reunião, alguns trabalhadores relataram que várias pessoas se interessaram pelo painel. Passando por ele, paravam e olhavam as informações, outros perguntavam do que se tratava.

Comentaram que os trabalhadores da manutenção viram o painel, mas nada falaram a respeito das fotos que indicavam a falta de manutenção das máquinas. No diálogo que se seguiu, os trabalhadores colocaram como hipótese que o problema de rapidez na manutenção estivesse relacionado com a falta de pessoal nesse setor ou com a falta de liberação para a compra de equipamentos necessários à manutenção.

Mas os trabalhadores lembraram que uma das máquinas, que funcionava no sistema manual, por causa de defeitos no sistema automático, finalmente havia sido enviada para o conserto. Ainda se referiram à reorganização dos cavaletes de chapas de pedras para melhorar o espaço de circulação dos trabalhadores na área de produção. 
O tempo todo indicavam que havia muito ainda a ser feito e que, embora tivessem acontecido algumas melhorias, era necessário que outras ações fossem realizadas.

Um trabalhador disse: "Esse é o caminho que nós temos para melhorar a situação". acatadas".

Outro trabalhador, avaliando a oficina afirmou: "É bom se as nossas ideias forem

Um participante sugeriu a realização de uma reunião com os proprietários da empresa e encarregados, mas, ao mesmo tempo, perguntou se todos se prontificavam a falar essas questões na reunião. Muitos ficaram calados. Outro trabalhador sugeriu uma segunda oficina de fotos mostrando o que havia mudado e o que não havia mudado, indagando por que algumas situações não mudam.

Depois de vários debates, os trabalhadores decidiram pela segunda oficina.

Dois trabalhadores se prontificaram a produzir as novas fotos. A partir das discussões do encontro anterior, produziram as fotos do que havia melhorado e do que não havia mudado. Dois dias após, reuniram-se a pesquisadora, os dois fotógrafos e mais dois trabalhadores. Após uma discussão do que queriam mostrar, os trabalhadores decidiram montar outro painel com as fotos antigas e novas, fazendo um antes e um depois das situações fotografadas. Acima das fotos, foram colocadas as palavras antes e depois, e criadas frases e um título para o painel: "Pequenos problemas sempre haverão, o que não podemos deixar é que eles se tornem grandes problemas".

Vamos mostrar uma das mudanças apresentadas no painel (Fotos 5 e 6).

Antes faltava uma fresa no bisote 2. Essa máquina foi consertada. Os trabalhadores observam que, com o problema solucionado, não é mais necessário empurrar o material na esteira. Com isso, o funcionário que ficava ajudando a empurrar as pedras exerce outra função, trazendo beneficio não só para os funcionários como para a própria empresa.

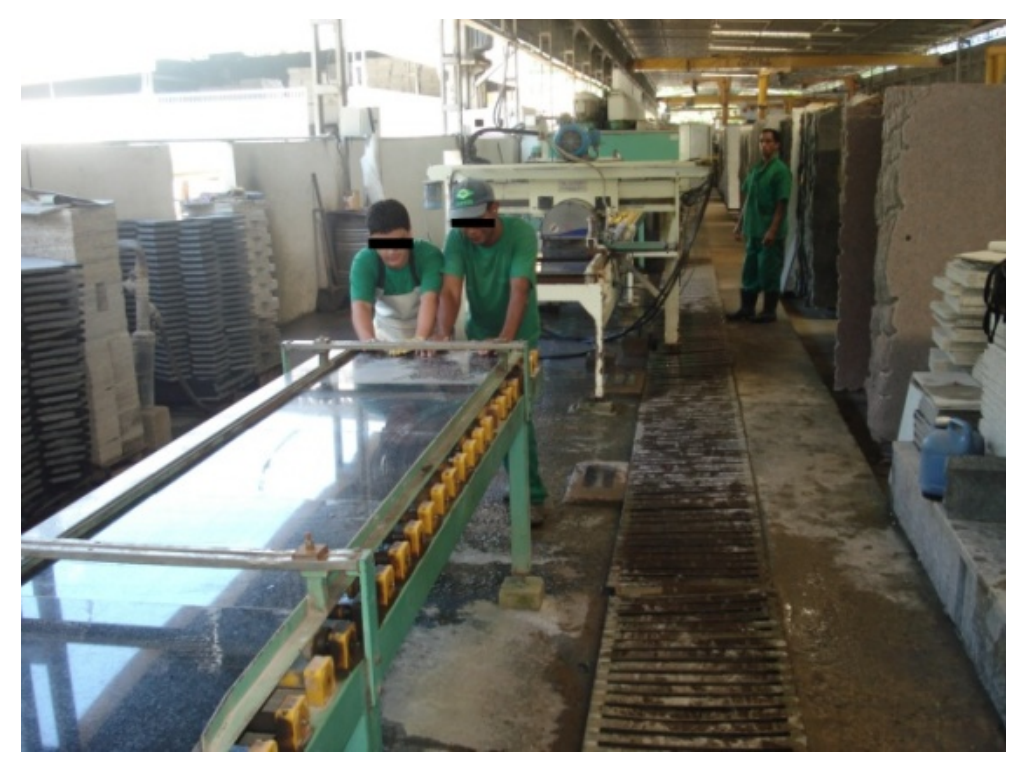

Foto 5: Antes (Extraída de Pacheco, Barros e Osorio, 2012) 


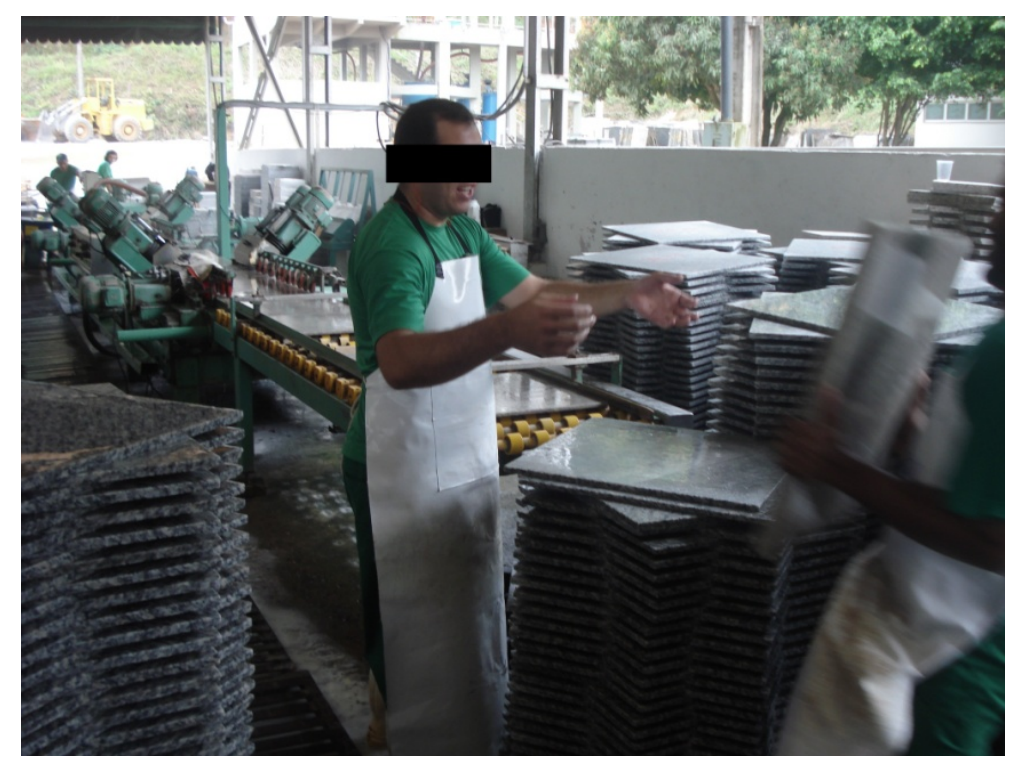

Foto 6: Depois (Extraída de Pacheco, Barros e Osorio, 2012)

\section{Considerações finais}

As oficinas que temos realizado têm, como pôde ser observado, diferenças que são o resultado de cada processo singular.

Como algo comum a todas as experiências, temos a tarefa como provocadora de um importante deslocamento: desloca-se o trabalhador para o lugar de observador e analista do seu trabalho. $\mathrm{O}$ analista/pesquisador do trabalho assessora e facilita esse debate.

O debate se faz sobre uma marca do trabalho: uma marca produzida coletivamente, já como fruto do diálogo que põe o gênero em manutenção. Desse modo, o debate se faz sobre a atividade, evitando a personalização e o julgamento sobre as escolhas individuais. E o debate se faz de modo recorrente, favorecendo elaborações e reelaborações nas análises que se produzem. Nesse processo, há momentos em que poderíamos dizer que se dão "autoconfrontações simples", consigo mesmo, com a situação fotografada e o analista do trabalho como provocador; em outros, ocorrem as "autoconfrontações cruzadas", em que os pares são os principais provocadores da análise.

É preciso afirmar que tais estratégias metodológicas só se viabilizam por uma postura ético-política que, ao perseguir a ampliação de mundos, e não seu encurtamento, considera imprescindível a inclusão do trabalhador nos caminhos investigativos.

A ênfase na aliança que se faz com os trabalhadores implica uma relação de confiança, "fiar com". Essa relação de confiança deve ser construída entre trabalhadores e analista, mas sobretudo entre trabalhadores e em cada trabalhador.

Embora intervenções como as aqui relatadas possam suscitar - e é bom que isso ocorra - melhoras no processo de produção ou uma maior atenção à saúde do trabalhador, de modo algum o objetivo destas é o aumento da produtividade e do lucro.

O objetivo é deixar mais claro e presente o poder que os trabalhadores têm, sobretudo enquanto coletivo, sobre seu meio de trabalho. É ampliar a possibilidade de o trabalho real retroagir sobre o trabalho prescrito, transformando-o. 
O que estamos afirmando é uma direção de pesquisa que se efetiva com a participação na investigação dos envolvidos no processo de análise, garantindo protagonismo efetivo do coletivo constituído por pesquisadores e trabalhadores. Nessa direção, as relações se transformam por um momento, trabalhadores e analistas/pesquisadores podem compreender certos aspectos do trabalho.

Desejamos que façam bom uso desse saber.

\section{Referências}

Barros, M. E. B. \& Oliveira, S. P. (2004). Construindo formas de co-gestão do trabalho docente: as comunidades ampliadas de pesquisa como estratégia privilegiada. In Anais da Reunião Anual da Associação Nacional de Pós-Graduação e Pesquisa em Educação. Caxambu, Minas Gerais. Associação Nacional de Pós-Graduação e Pesquisa em Educação.

Clot, Y. (2010). Trabalho e poder de agir. Belo Horizonte: Fabrefactum.

Clot, Y. (2006). A função psicológica do trabalho. Petrópolis: Vozes.

Clot, Y. \& Faïta, D. (2000). Genres et styles en analyse du travail: concepts et méthodes. Travailler, 4, 7-42.

Litim. M. (2006). Les histoires du travail: un instrument du développement du métier et de l'activité professionnelle. Une analyse de l'activité soignante en gérontologie. Tese de Doutorado, Ecole Doctorale ETE, Laboratoire de Psychologie du Travail, Conservatoire des Arts et Metiers, Paris, França.

Osório da Silva, C. et al. (2011). Clínica da atividade. In P. F. Bendassolli \& L. Soboll (Orgs.). Clínicas do trabalho: novas perspectivas para compreensão do trabalho na atualidade (pp. 188-203). São Paulo: Atlas.

Osorio, C. (2010). Experimentando a fotografia como ferramenta de análise da atividade de trabalho. Informática na Educação, 13, 41-49.

Pacheco, A. B. (2010). Homens e mulheres do mármore e do granito: entre cores e ritmos. Dissertação de Mestrado, Programa de Pós-Graduação em Psicologia Institucional, Universidade Federal de Espírito Santo, Vitória.

Pacheco, A., Barros, M. E. \& Osorio, C. (2012). Trabalhar o mármore e o granito: entre cores e ritmos. Cadernos de Psicologia Social do Trabalho, 15 (2), 255-270.

\section{Endereço para correspondência}

claudiaosorio@terra.com.br, ariele.binoti@hotmail.com, betebarros@uol.com.br 